\title{
気体浸透と熱伝導を受ける多孔質半無限体の熱応力*
}

荒井 正行 ${ }^{* 1}$

\section{Thermal Stress of Porous Semi Infinite Media Subjected to Gas Infiltration and Heat Transfer}

\author{
Masayuki ARAI ${ }^{* 1}$ \\ ${ }^{* 1}$ Central Research Institute of Electric Power Industry \\ Nagasaka 2-6-1, Yokosuka-si, Kanagawa, 240-0196, Japan
}

\begin{abstract}
When a porous solid is subjected to both gas infiltration and heat transfer, thermal stresses are generated in such a solid. In the previous repot, fundamental theory for a porous solid under such a complex situation was developed. In this study, a thermal stress problem for a porous solid with a flat boundary surface, which is generally called a semi-infinite space, subjected to a concentrated point loading is investigated. A method of solution based upon displacement potential and Fourier integral transform techniques is applied to solve the problem. Closed form solutions of the gas pressure, solid temperature and thermal stress fields in semi-infinite porous media are presented. It is shown that the thermal stress solution for the problem includes only a free expansion term caused due to the gas pressure and external pressure at the free boundary surface.
\end{abstract} Numerical results reveal that the thermal stress increases with the gas permeability $(\kappa / \zeta)$.

Key Words : Elasticity, Porous Solid, Gas Infiltration, Heat Transfer, Thermal Stress, Semi-Infinite Problem

\section{1. 緒言}

定常温度場のような調和関数で与えられる場 $\left(V \in \mathbb{R}^{3}\right)$ のもとで生じる熱応力について考えてみる. もし場が単 連結な領域であり, 領域境界面 $(S \subset V)$ で変位 $\left(u_{i}\right)$ に関する境界条件が与えられておらず, その領域内部には熱源 がなければ熱忘力は発生しないことが知られている(1),(2). 例えば，無限体中に熱源がある場合には熱応力を生じ るが，自由表面上に熱源がある場合には熱応力が消失する.

ところで著者は,これまでに気体浸透と熱伝導を受ける多孔質体の熱弾性理論について検討した ${ }^{(3)}$. そこでは, 多孔質体中を浸透する気体圧力 $(P)$ が Laplace 方程式を満足すること, 固体温度 $\left(t_{s}\right)$ と気体圧力の二乗の和で与え られる物理量 $(\Phi)$ が Laplace 方程式を満足することを示した. また, 気体の浸透と熱伝導を受けた多孔質体におけ る自由膨張項は, 固体温度の変化により生じる熱膨張 $\left(\alpha t_{s}\right)$ と気孔壁面に作用寸る気体の膨張のふたつの効果を含 むことも示してきた．固体温度場は気体圧力の二乗項からなる非線形項を含むため一般には熱灾力の㛜密解を求 めることは困難である. しかしながら，いくつかの単純な形状と境界条件の問題に対しては厳密解を求めること ができる. その問題のひとつとして, 本研究では二次元多孔質半無限体の自由表面上に気体圧力, 温度を集中し て受けるような熱忘力問題をとりあげる．多孔質体の自由膨張項に熱膨張の効果のみを含むのであれば，上述し たように熱忘力は発生しないが, 気体による膨張の効果によって熱灾力が生じるものと考えられる. 本問題では, このような自由膨張の効果が多孔質半無限体に生じる応力場にどのように影響を及ぼすのか明らかにする.

\section{2. 基礎理論}

\footnotetext{
* 原稿受付 2012 年 9 月 18 日

*1 正員, (一財) 電力中央研究所 材料科学研究所（广240-0196 神奈川県横須賀市長坂 2-6-1） (現 東京理科大学工学部第一部機械工学科)

E-mail: marai@rs.tus.ac.jp
} 
直角座標系 $x_{j} \in \mathbb{R}^{3}$ における多孔質体中の気孔間を浸透する気体圧力 $P\left(x_{j}\right)$ に関する方程式

$$
\partial_{i} \partial_{i} P\left(x_{j}\right)=0
$$

また，気体圧力と固体温度の連成方程式

$$
\partial_{i} \partial_{i} \Phi\left(t_{s}, P\right)=0
$$

を適当な境界条件のもとで解くことで, 多孔質体を浸透する気体の状態量（気体圧力 $P$, 気体の流速 $v_{i}=$ $\left.-\left(\frac{\kappa}{s}\right) \partial_{i} P\right)$, 固体温度 $\left(t_{s}\right)$ が得られることを前報 ${ }^{(3)}$ で示した. ここで, $\partial_{i}=\partial / \partial x_{i}$ ならびに $\Phi=t_{s}+\omega P^{2}$ である.

また， $\omega=\frac{c_{p}}{2 R k_{s}}\left(\frac{\kappa}{\varsigma}\right), \quad c_{p}$ は定圧比熱， $R$ はガス定数， $k_{s}$ は多孔質体全体のみかけ上の熱伝導率， $\left(\frac{\kappa}{\varsigma}\right)$ は多孔質体中 の気体の透過係数である.

一方，多孔質体に対する一般化された Hooke の法則は,

$$
\varepsilon_{i j}=\frac{1}{2 \mu}\left\{\chi_{1} \sigma_{i j}-\chi_{2} \delta_{i j} \sigma_{k k}\right\}+\frac{3}{2}\left(\frac{\phi}{\mu}\right) P_{i j}+\alpha_{i j} t_{s}
$$

で与えられる ${ }^{(3)}$.ここで, $\mu$ は横弾性係数, $\phi$ は気孔率, $\alpha_{i j}=\alpha \delta_{i j}$ であり, $\alpha$ は熱膨張係数, $P_{i j}=P \delta_{i j}$ である. また，

$$
\chi_{1}=1+15\left(\frac{1-v}{7-5 v}\right) \phi, \quad \chi_{2}=\frac{v}{1+v}+\frac{3}{2}\left(\frac{1-v}{1+v}\right)\left(\frac{1+5 v}{7-5 v}\right) \phi
$$

であり，vはポアソン比である.

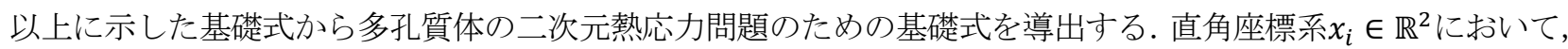
気体圧力に関する方程式(1)は,

$$
\partial_{1}^{2} P+\partial_{2}^{2} P=0
$$

また，気体圧力と固体温度の連成方程式(2)は，

$$
\partial_{1}^{2} \Phi+\partial_{2}^{2} \Phi=0
$$

となる.

つぎに，二次元問題に対する Hooke の法則は，一般化された Hooke の法則(3)からつぎのように導かれる.

$$
\begin{aligned}
& \frac{\sigma_{11}}{2 \mu}=\frac{1}{\chi_{1}}\left\{\varepsilon_{11}+\frac{\chi_{2}}{\chi_{1}-n \chi_{2}} e\right\}-\frac{1}{2\left(\chi_{1}-n \chi_{2}\right)} F \\
& \frac{\sigma_{22}}{2 \mu}=\frac{1}{\chi_{1}}\left\{\varepsilon_{22}+\frac{\chi_{2}}{\chi_{1}-n \chi_{2}} e\right\}-\frac{1}{2\left(\chi_{1}-n \chi_{2}\right)} F \\
& \frac{\sigma_{12}}{2 \mu}=\frac{1}{\chi_{1}} \varepsilon_{12}
\end{aligned}
$$

ここで, 
$n=\left\{\begin{array}{l}2 \text { (Plane stress }) \\ 3 \text { (Plane strain })\end{array}\right.$

によって平面応力問題と平面ひずみ問題を区別する。また,

$$
F=3\left(\frac{\phi}{\mu}\right) P+2 \alpha t_{s}
$$

ならびに，

$$
e=\partial_{i} u_{i}
$$

である.なお，式(3)において $\sigma_{i j}=0$ とすると，

$$
\varepsilon_{i j}=\frac{3}{2}\left(\frac{\phi}{\mu}\right) P_{i j}+\alpha_{i j} t_{s}
$$

となり，これにより温度と気体圧力の変化に伴って生じる自由膨張量は，

$$
e=3\left(\frac{\phi}{\mu}\right) P+2 \alpha t_{s}
$$

で与えられるが，これはFに等しい.

つぎに Navier の式を導出する. 物体力が存在しないときの応力のテンソル方程式は,

$$
\partial_{1} \sigma_{11}+\partial_{2} \sigma_{12}=0, \quad \partial_{1} \sigma_{12}+\partial_{2} \sigma_{22}=0
$$

であり，式(8)に式(7)を代入するとともに，

$$
\varepsilon_{i j}=\frac{1}{2}\left(\partial_{i} u_{j}+\partial_{j} u_{i}\right)
$$

を考慮してそれぞれの方程式を整理すると，つぎの二次元熱応力問題に対する Navier の式を得る.

$$
\partial_{i} \partial_{i} u_{j}+\frac{\chi_{1}-(n-2) \chi_{2}}{\chi_{1}-n \chi_{2}} \partial_{j} e=\frac{\chi_{1}}{\chi_{1}-n \chi_{2}} \partial_{j} F
$$

\section{3. 変位ポテンシャルによる二次元問題の解法}

変位ポテンシャル関数 $\psi$ を利用して，変位成分 $\left(u_{i}\right)$ をつぎのようにおく.

$$
u_{i}=\Psi_{i}+\partial_{i} \psi
$$

ここで， $\Psi_{i}$ は式(10)の一般解であり，つぎの同次方程式 


$$
\partial_{i} \partial_{i} \Psi_{j}+\frac{\chi_{1}-(n-2) \chi_{2}}{\chi_{1}-n \chi_{2}} \partial_{j} E=0
$$

を満足するものとする．ここで， $E=\partial_{i} \Psi_{i}$ である.

また, 変位ポテンシャル関数

$$
\partial_{i} \partial_{i} \psi=\frac{\chi_{1} F}{2\left(\chi_{1}-(n-1) \chi_{2}\right)}
$$

を満足しなければならない.

以上により得られる変位成分(11)ならびに応力成分が対象とする問題の境界条件を満たすようにすればよい.

\section{4. 温度と気体圧力を集中して表面に受ける二次元多孔質半無限体の熱応力問題}

本研究では, 温度 $t_{0}$ と気体圧力 $p_{0}$ を集中して表面に受けている二次元多孔質半無限体の熱忘力問題について考 える. この問題を解くために図 1 に示すように 3 つの問題に分離する. 寸なわち, (a)気体圧力の問題, (b)固体温 度の問題，(c)熱応力の問題．それぞれの問題に対応する境界条件はつぎのように与えられる.

$$
\begin{array}{lr}
P\left(x_{1}, 0\right)=p_{0} b \delta\left(x_{1}\right) & (14-a) \\
t_{s}\left(x_{1}, 0\right)=t_{0} b \delta\left(x_{1}\right) & (14-b) \\
\sigma_{22}\left(x_{1}, 0\right)=-p_{0} b \delta\left(x_{1}\right) & (14-c) \\
\sigma_{12}\left(x_{1}, 0\right)=0 & (14-d)
\end{array}
$$

ここで， $\delta(\cdot)$ は Dirac のデルタ関数である. デルタ関数は長さの逆数の次元をもつ有次元量である. このため, 式(14)の右辺と左辺の次元をそろえるために見かけ上，長さの次元をもつbを Dirac のデルタ関数に作用させてお いた．基本的にはbは単位量として考えてよい

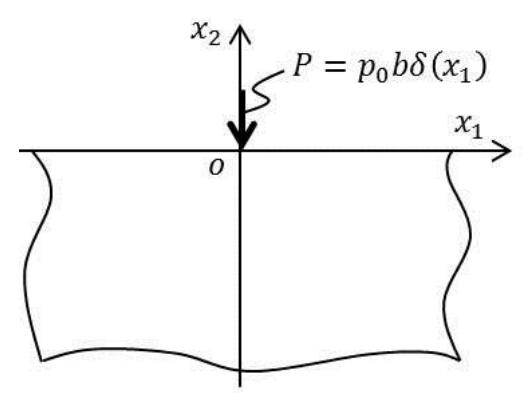

[a] Pressure field

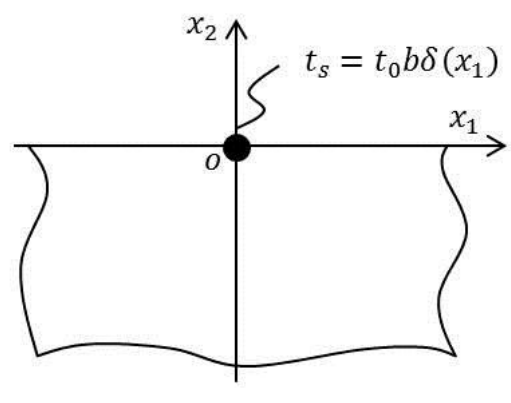

[b] Solid temperature field

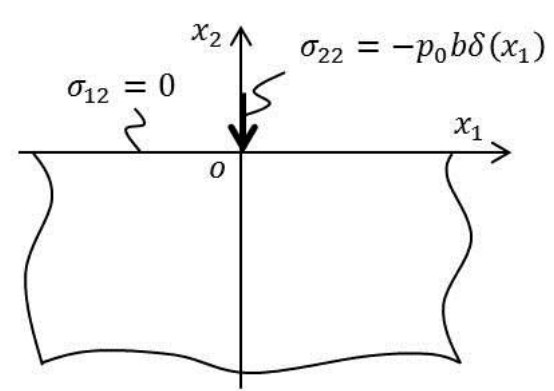

[c] Stress field

Fig.1 Porous semi-infinite media subjected to a concentrated pressure and temperature at free-surface

はじめに，問題(a)に示す気体圧力の問題について考える. 気体圧力に関する方程式(5)を解くために, 圧力 $P$ 対して Fourier 変換を施す．本研究では，Sneddonにより導入された Fourier 変換 ${ }^{(4)} の$ 定義に従う.すなわち, 


$$
\begin{aligned}
& \mathcal{F}\left[P\left(x_{1}, x_{2}\right)\right]=\hat{P}\left(\xi, x_{2}\right)=\int_{-\infty}^{\infty} P\left(x_{1}, x_{2}\right) \exp \left(i \xi x_{1}\right) d x_{1} \\
& \mathcal{F}^{-1}\left[\hat{P}\left(\xi, x_{2}\right)\right]=P\left(x_{1}, x_{2}\right)=\frac{1}{2 \pi} \int_{-\infty}^{\infty} \hat{P}\left(\xi, x_{2}\right) \exp \left(-i \xi x_{1}\right) d \xi
\end{aligned}
$$

ここで, $P \subset \mathbb{R}, \hat{P} \subset \mathbb{C}$ である, また，原関数に対して像関数には々を付けることでそれぞれの関数を区別する. 式(5)に Fourier 変換(15)を施すとともに， $x_{2} \rightarrow-\infty に て P \rightarrow 0$ に漸近することを考慮することで本問題の一般解

$$
P\left(x_{1}, x_{2}\right)=\frac{1}{2 \pi} \int_{-\infty}^{\infty} A(\xi) \exp \left(-i \xi x_{1}+|\xi| x_{2}\right) d \xi
$$

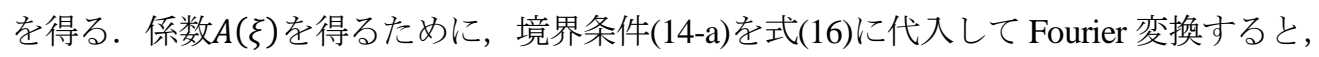

$$
\begin{aligned}
& \mathrm{A}(\xi)=\int_{-\infty}^{\infty} p_{0} b \delta\left(x_{1}\right) \exp \left(i \xi x_{1}\right) d x_{1}=p_{0} b \\
& \text { よって, 式(16)は, } \\
& P\left(x_{1}, x_{2}\right)=\frac{p_{0} b}{2 \pi} \int_{-\infty}^{\infty} \exp \left(-i \xi x_{1}+|\xi| x_{2}\right) d \xi \\
& \Rightarrow \frac{2}{\pi} p_{0} b \int_{0}^{\infty} \exp \left(\xi x_{2}\right) \cos \left(\xi x_{1}\right) d \xi
\end{aligned}
$$

となり，無限積分を実行することで気体の圧力解

$$
P\left(x_{1}, x_{2}\right)=-\frac{2}{\pi} p_{0}\left(\frac{b x_{2}}{x_{1}^{2}+x_{2}^{2}}\right)
$$

を得る。

つぎに問題(b)の固体温度の問題について考える. この問題においては式(6)を解けばよいが, 式(18)の圧力解を 利用することで簡単に固体温度解を得ることができる．まず，式(5)と式(6)のアナロジーに注目すると，

$$
\Phi\left(x_{1}, x_{2}\right)=-\frac{2}{\pi} \Phi_{0}\left(\frac{b x_{2}}{x_{1}^{2}+x_{2}^{2}}\right)
$$

ここで,

$$
\Phi=t_{s}+\omega P^{2}, \quad \Phi_{0}=t_{0}+\omega P_{0}^{2}
$$

により式(19)から固体温度解

$$
t_{s}\left(x_{1}, x_{2}\right)=-\frac{2}{\pi}\left(t_{0}+\omega p_{0}^{2}\right)\left(\frac{b x_{2}}{x_{1}^{2}+x_{2}^{2}}\right)-\left(\frac{2}{\pi}\right)^{2} \omega p_{0}^{2}\left(\frac{b x_{2}}{x_{1}^{2}+x_{2}^{2}}\right)^{2}
$$

を得る．ここで，気体の圧力解(18)の右辺，ならびに固体温度解(20)の右辺第一項は調和関数である. 
最後に問題(c)に示寸熱応力問題について考える.このために非同次偏微分方程式(13)をつぎのように変形して $お く$.

$$
2(1-(n-1) \bar{v}) \partial_{i} \partial_{i} \psi=F
$$

ここで， $\bar{v}=\chi_{2} / \chi_{1}$ である. 式(21)に圧力解(18)と固体温度解(20)を代入して整理すると，

$$
2(1-(n-1) \bar{v}) \partial_{i} \partial_{i} \psi=-\frac{1}{\pi} k_{1}\left(\frac{x_{2}}{x_{1}^{2}+x_{2}^{2}}\right)-k_{2}\left(\frac{x_{2}}{x_{1}^{2}+x_{2}^{2}}\right)^{2}
$$

ここで,

$$
\begin{aligned}
& k_{1}=2\left[3\left(\frac{\phi}{\mu}\right) p_{0}+2 \alpha\left(t_{0}+\omega p_{0}^{2}\right)\right] b \\
& k_{2}=2 \alpha \omega\left(\frac{2}{\pi} p_{0}\right)^{2} b^{2}
\end{aligned}
$$

である.

この特解が，

$$
2(1-(n-1) \bar{v}) \psi=-\frac{1}{4 \pi} k_{1} x_{2}\left(\ln \left(x_{1}^{2}+x_{2}^{2}\right)-1\right)-\frac{1}{16} k_{2}\left\{\left(\ln \left(x_{1}^{2}+x_{2}^{2}\right)\right)^{2}+2\left(\frac{x_{1}^{2}-x_{2}^{2}}{x_{1}^{2}+x_{2}^{2}}\right)\right\}
$$

のように与えられることは式(22)に代入することで容易に確認できる.

この特解に対応した応力成分 $\sigma_{i j}^{\prime}$ は, 式(7)より,

$\frac{1-n \bar{v}}{2 \mu} \chi_{1} \sigma_{11}^{\prime}=(1-n \bar{v}) \varepsilon_{11}+\bar{v} e-\frac{1}{2} F$

$\frac{1-n \bar{v}}{2 \mu} \chi_{1} \sigma_{22}^{\prime}=(1-n \bar{v}) \varepsilon_{22}+\bar{v} e-\frac{1}{2} F$

$\frac{1-n \bar{v}}{2 \mu} \chi_{1} \sigma_{12}^{\prime}=(1-n \bar{v}) \varepsilon_{12}$

式(9)ならびに変位ポテンシャル関数

$$
u_{i}=\partial_{i} \psi
$$

を式(24)に代入するとともに式(21)を考慮しながらそれぞれの式を整理すると，

$$
\begin{aligned}
& \frac{1}{2 \mu} \chi_{1} \sigma_{11}^{\prime}=-\partial_{2}^{2} \psi \\
& \frac{1}{2 \mu} \chi_{1} \sigma_{22}^{\prime}=-\partial_{1}^{2} \psi \\
& \frac{1}{2 \mu} \chi_{1} \sigma_{12}^{\prime}=\partial_{1} \partial_{2} \psi
\end{aligned}
$$


を得る. 式(25)に式(23)を代入すると, 特解に対応した応力成分 $\sigma_{i j}^{\prime}$ がつぎのように得られる.

$$
\begin{aligned}
& \frac{1-(n-1) \bar{v}}{\mu} \chi_{1} \sigma_{11}^{\prime}=\frac{1}{2 \pi} k_{1} \frac{x_{2}\left(3 x_{1}^{2}+x_{2}^{2}\right)}{\left(x_{1}^{2}+x_{2}^{2}\right)^{2}}+\frac{1}{4} k_{2}\left[\frac{\left(x_{1}^{2}-x_{2}^{2}\right)\left\{\ln \left(x_{1}^{2}+x_{2}^{2}\right)-2\right\}}{\left(x_{1}^{2}+x_{2}^{2}\right)^{2}}+8 \frac{x_{1}^{2} x_{2}^{2}}{\left(x_{1}^{2}+x_{2}^{2}\right)^{3}}\right] \\
& \frac{1-(n-1) \bar{v}}{\mu} \chi_{1} \sigma_{22}^{\prime}=\frac{1}{2 \pi} k_{1} \frac{x_{2}\left(-x_{1}^{2}+x_{2}^{2}\right)}{\left(x_{1}^{2}+x_{2}^{2}\right)^{2}}+\frac{1}{4} k_{2}\left[\frac{\left(-x_{1}^{2}+x_{2}^{2}\right) \ln \left(x_{1}^{2}+x_{2}^{2}\right)}{\left(x_{1}^{2}+x_{2}^{2}\right)^{2}}+2 \frac{\left(x_{1}^{2}-x_{2}^{2}\right)^{2}}{\left(x_{1}^{2}+x_{2}^{2}\right)^{3}}\right] \\
& \frac{1-(n-1) \bar{v}}{\mu} \chi_{1} \sigma_{12}^{\prime}=-\frac{1}{2 \pi} k_{1} \frac{x_{1}\left(x_{1}^{2}-x_{2}^{2}\right)}{\left(x_{1}^{2}+x_{2}^{2}\right)^{2}}+\frac{1}{2} k_{2} x_{1} x_{2}\left[\frac{\ln \left(x_{1}^{2}+x_{2}^{2}\right)}{\left(x_{1}^{2}+x_{2}^{2}\right)^{2}}-\frac{3 x_{1}^{2}-x_{2}^{2}}{\left(x_{1}^{2}+x_{2}^{2}\right)^{3}}\right]
\end{aligned}
$$

つぎに，同次偏微分方程式(12)に対する一般解 $u_{i}=\Psi_{i}$ を求める. ただし，ここではこの同次方程式から直接一 般解を求めず，つぎのような手順で一般解に対応した応力成分 $\sigma_{i j}^{\prime \prime}$ を求めることとした.

二次元問題に対する Hooke の法則(7)において, $F=0$ とおいてひずみ成分 $\varepsilon_{i j}$ について求めると,

$$
\begin{aligned}
& \varepsilon_{11}=\frac{1}{2 \mu} \chi_{1}\left(\sigma_{11}-\frac{\bar{v}}{1-(n-2) \bar{v}}\left(\sigma_{11}+\sigma_{22}\right)\right) \\
& \varepsilon_{22}=\frac{1}{2 \mu} \chi_{1}\left(\sigma_{22}-\frac{\bar{v}}{1-(n-2) \bar{v}}\left(\sigma_{11}+\sigma_{22}\right)\right) \\
& \varepsilon_{12}=\frac{1}{2 \mu} \chi_{1} \sigma_{12}
\end{aligned}
$$

これらの式をひずみの適合条件式

$$
\partial_{2} \partial_{2} \varepsilon_{11}+\partial_{1} \partial_{1} \varepsilon_{22}=2 \partial_{1} \partial_{2} \varepsilon_{12}
$$

に代入するとともに, 応力関数 $\Lambda\left(x_{1}, x_{2}\right)$

$$
\sigma_{11}=\partial_{2}^{2} \Lambda, \quad \sigma_{22}=\partial_{1}^{2} \Lambda, \sigma_{12}=-\partial_{1} \partial_{1} \Lambda
$$

を代入して整理すると，応力関数に関するつぎの重調和方程式

$$
\partial_{i} \partial_{i} \partial_{j} \partial_{j} \Lambda=0
$$

を得る. 本研究では，この重調和方程式を解くことによって式(12)に対応した応力成分 $\sigma_{i j}^{\prime \prime}$ 求める.

この方程式を解くために，応力関数 $\Lambda\left(x_{1}, x_{2}\right)$ に対してつぎの Fourier 変換を導入する.

$$
\begin{aligned}
& \mathcal{F}\left[\Lambda\left(x_{1}, x_{2}\right)\right]=\hat{\Lambda}\left(\xi, x_{2}\right)=\int_{-\infty}^{\infty} \Lambda\left(x_{1}, x_{2}\right) \exp \left(i \xi x_{1}\right) d x_{1} \\
& \mathcal{F}^{-1}\left[\hat{\Lambda}\left(\xi, x_{2}\right)\right]=\Lambda\left(x_{1}, x_{2}\right)=\frac{1}{2 \pi} \int_{-\infty}^{\infty} \hat{\Lambda}\left(\xi, x_{2}\right) \exp \left(-i \xi x_{1}\right) d \xi
\end{aligned}
$$

ここで, $\Lambda \subset \mathbb{R}, \hat{\Lambda} \subset \mathbb{C}$ である.

重調和方程式(30)に Fourier 変換を施すとともに, $x_{2} \rightarrow-\infty$ に対して $\sigma_{i j} \rightarrow 0$ に漸近することに注意すると, 本問 題の一般解は,

$$
\Lambda\left(x_{1}, x_{2}\right)=\frac{1}{2 \pi} \int_{-\infty}^{\infty}\left[A(\xi)+B(\xi) x_{2}\right] \exp \left(-i \xi x_{1}+|\xi| x_{2}\right) d \xi
$$


で与えられる. 式(33)を式(29)に代入することで応力成分

$$
\begin{aligned}
& \sigma_{11}^{\prime \prime}\left(x_{1}, x_{2}\right)=\frac{1}{2 \pi} \int_{-\infty}^{\infty}\left[A(\xi)|\xi|+B(\xi)\left(2+|\xi| x_{2}\right)\right]|\xi| \exp \left(-i \xi x_{1}+|\xi| x_{2}\right) d \xi \\
& \sigma_{22}^{\prime \prime}\left(x_{1}, x_{2}\right)=\frac{-1}{2 \pi} \int_{-\infty}^{\infty}\left[A(\xi)+B(\xi) x_{2}\right] \xi^{2} \exp \left(-i \xi x_{1}+|\xi| x_{2}\right) d \xi \\
& \sigma_{12}^{\prime \prime}\left(x_{1}, x_{2}\right)=\frac{i}{2 \pi} \int_{-\infty}^{\infty}\left[A(\xi)|\xi|+B(\xi)\left(1+|\xi| x_{2}\right)\right] \xi \exp \left(-i \xi x_{1}+|\xi| x_{2}\right) d \xi
\end{aligned}
$$

を得る．また，積分核の性質を考慮して式(34)を Fourier 余弦，正弦関数で表現するとつぎのようになる.

$$
\begin{aligned}
& \sigma_{11}^{\prime \prime}\left(x_{1}, x_{2}\right)=\frac{2}{\pi} \int_{0}^{\infty}\left[A(\xi) \xi+B(\xi)\left(2+\xi x_{2}\right)\right] \xi \exp \left(\xi x_{2}\right) \cos \left(\xi x_{1}\right) d \xi \\
& \sigma_{22}^{\prime \prime}\left(x_{1}, x_{2}\right)=\frac{-2}{\pi} \int_{0}^{\infty}\left[A(\xi)+B(\xi) x_{2}\right] \xi^{2} \exp \left(\xi x_{2}\right) \cos \left(\xi x_{1}\right) d \xi \\
& \sigma_{12}^{\prime \prime}\left(x_{1}, x_{2}\right)=\frac{2}{\pi} \int_{0}^{\infty}\left[A(\xi) \xi+B(\xi)\left(1+\xi x_{2}\right)\right] \xi \exp \left(\xi x_{2}\right) \sin \left(\xi x_{1}\right) d \xi
\end{aligned}
$$

結局, 式(35)の未定係数 $A(\xi)$ と $B(\xi)$ は,

$$
\left\{\begin{array}{l}
\sigma_{11} \\
\sigma_{22} \\
\sigma_{12}
\end{array}\right\}=E q \cdot(26)+E q \cdot(35)
$$

が境界条件(14-c), (14-d)を満足するよう定める. すなわち, つぎの連立積分方程式

$$
\begin{aligned}
& \frac{-2}{\pi} \int_{0}^{\infty} A(\xi) \xi^{2} \cos \left(\xi x_{1}\right) d \xi+\frac{1}{2} \frac{\mu k_{2}}{(1-(n-1) \bar{v}) \chi_{1}}\left(\frac{1-\ln \left|x_{1}\right|}{x_{1}^{2}}\right)=-p_{0} b \delta\left(x_{1}\right) \\
& \frac{2}{\pi} \int_{0}^{\infty}[A(\xi) \xi+B(\xi)] \xi \sin \left(\xi x_{1}\right) d \xi-\frac{1}{2 \pi} \frac{\mu k_{1}}{(1-(n-1) \bar{v}) \chi_{1}}\left(\frac{1}{x_{1}}\right)=0
\end{aligned}
$$

\section{を解けばよい，}

はじめに式(37)に対して Fourier 変換すると,

$$
[A(\xi) \xi+B(\xi)] \xi=\frac{1}{2 \pi} \frac{\mu k_{1}}{(1-(n-1) \bar{v}) \chi_{1}} \int_{0}^{\infty} \frac{\sin \left(\xi x_{1}\right)}{x_{1}} d x_{1}
$$

となり，無限積分を実行することにより，

$$
\xi(A(\xi) \xi+B(\xi))=\frac{1}{4} \frac{\mu k_{1}}{(1-(n-1) \bar{v}) \chi_{1}}
$$

\section{を得る。}

つぎに式(36)に対して Fourier 変換すると, 


$$
A(\xi) \xi^{2}=p_{0} b+\frac{1}{2} \frac{\mu k_{2}}{(1-(n-1) \bar{v}) \chi_{1}} \int_{0}^{\infty} \frac{1-\ln \left|x_{1}\right|}{x_{1}^{2}} \cos \left(\xi x_{1}\right) d x_{1}
$$

ここで，積分公式（付録 A）

$$
\int_{0}^{\infty} \frac{\ln \left|x_{1}\right|}{x_{1}^{2}} \cos \left(\xi x_{1}\right) d x_{1}=\frac{\pi}{2} \xi(\ln \xi-1+\gamma)
$$

を利用することで，

$$
A(\xi) \xi^{2}=p_{0} b-\frac{\pi}{4} \frac{\mu k_{2}}{(1-(n-1) \bar{v}) \chi_{1}} \xi(\ln \xi+\gamma)
$$

を得る.ここで, オイラーの定数 $\gamma=\lim _{n \rightarrow \infty}\left(1+\frac{1}{2}+\cdots+\frac{1}{n}-\ln n\right)$ である.

さらに，式(39)を式(38)に代入して，

$$
B(\xi) \xi=-p_{0} b+\frac{1}{4} \frac{\mu k_{1}}{(1-(n-1) \bar{v}) \chi_{1}}+\frac{\pi}{4} \frac{\mu k_{2}}{(1-(n-1) \bar{v}) \chi_{1}} \xi(\ln \xi+\gamma)
$$

\section{を得る.}

以上により, 式(39)と(40)を式(35)に代入し, 特解 (26)と重ね合わせることで応力成分はつぎのようになる.

$$
\begin{aligned}
& \frac{(1-(n-1) \bar{v})}{\mu} \chi_{1} \sigma_{11} \\
& =\frac{2}{\pi} \int_{0}^{\infty}\left[-\frac{(1-(n-1) \bar{v})}{\mu} \chi_{1} p_{0} b\left(1+\xi x_{2}\right)+\frac{1}{4} k_{1}\left(2+\xi x_{2}\right)+\frac{\pi}{4} k_{2}\left(1+\xi x_{2}\right) \xi(\ln \xi+\gamma)\right] \exp \left(\xi x_{2}\right) \cos \left(\xi x_{1}\right) d \xi \\
& +\frac{1}{2 \pi} k_{1} \frac{x_{2}\left(3 x_{1}^{2}+x_{2}^{2}\right)}{\left(x_{1}^{2}+x_{2}^{2}\right)^{2}}+\frac{1}{4} k_{2}\left[\frac{\left(x_{1}^{2}-x_{2}^{2}\right)\left\{\ln \left(x_{1}^{2}+x_{2}^{2}\right)-2\right\}}{\left(x_{1}^{2}+x_{2}^{2}\right)^{2}}+8 \frac{x_{1}^{2} x_{2}^{2}}{\left(x_{1}^{2}+x_{2}^{2}\right)^{3}}\right] \\
& \frac{(1-(n-1) \bar{v})}{\mu} \chi_{1} \sigma_{22} \\
& =\frac{-2}{\pi} \int_{0}^{\infty}\left[\frac{(1-(n-1) \bar{v})}{\mu} \chi_{1} p_{0} b\left(1-\xi x_{2}\right)+\frac{1}{4} k_{1}\left(\xi x_{2}\right)-\frac{\pi}{4} k_{2}\left(1-\xi x_{2}\right) \xi(\ln \xi+\gamma)\right] \exp \left(\xi x_{2}\right) \cos \left(\xi x_{1}\right) d \xi \\
& +\frac{1}{2 \pi} k_{1} \frac{x_{2}\left(-x_{1}^{2}+x_{2}^{2}\right)}{\left(x_{1}^{2}+x_{2}^{2}\right)^{2}}+\frac{1}{4} k_{2}\left[\frac{\left(-x_{1}^{2}+x_{2}^{2}\right) \ln \left(x_{1}^{2}+x_{2}^{2}\right)}{\left(x_{1}^{2}+x_{2}^{2}\right)^{2}}+2 \frac{\left(x_{1}^{2}-x_{2}^{2}\right)^{2}}{\left(x_{1}^{2}+x_{2}^{2}\right)^{3}}\right] \\
& \frac{(1-(n-1) \bar{v})}{\mu} \chi_{1} \sigma_{12} \\
& =\frac{2}{\pi} \int_{0}^{\infty}\left[-\frac{(1-(n-1) \bar{v})}{\mu} \chi_{1} p_{0} b\left(\xi x_{2}\right)+\frac{1}{4} k_{1}\left(1+\xi x_{2}\right)+\frac{\pi}{4} k_{2}\left(\xi x_{2}\right) \xi(\ln \xi+\gamma)\right] \exp \left(\xi x_{2}\right) \sin \left(\xi x_{1}\right) d \xi \\
& -\frac{1}{2 \pi} k_{1} \frac{x_{1}\left(x_{1}^{2}-x_{2}^{2}\right)}{\left(x_{1}^{2}+x_{2}^{2}\right)^{2}}+\frac{1}{2} k_{2} x_{1} x_{2}\left[\frac{\ln \left(x_{1}^{2}+x_{2}^{2}\right)}{\left(x_{1}^{2}+x_{2}^{2}\right)^{2}}-\frac{3 x_{1}^{2}-x_{2}^{2}}{\left(x_{1}^{2}+x_{2}^{2}\right)^{3}}\right]
\end{aligned}
$$

付録(B)に記載した積分公式を参考にしながら，式(41)に含まれる積分を実行するとともに式を整理することで 本問題の応力成分 


$$
\begin{aligned}
& \frac{(1-(n-1) \bar{v}) \pi}{4 \mu} \chi_{1} \sigma_{11} \\
& =\frac{(1-(n-1) \bar{v})}{\mu} \chi_{1} p_{0} b \frac{x_{1}^{2} x_{2}}{\left(x_{1}^{2}+x_{2}^{2}\right)^{2}} \\
& +\alpha \omega p_{0}^{2} \frac{b^{2}}{\pi}\left[x_{2}^{2} \frac{13 x_{1}^{2}-3 x_{2}^{2}}{\left(x_{1}^{2}+x_{2}^{2}\right)^{3}}-2 \frac{x_{1}^{2}-x_{2}^{2}}{\left(x_{1}^{2}+x_{2}^{2}\right)^{2}}+x_{1}^{2} \frac{x_{1}^{2}-3 x_{2}^{2}}{\left(x_{1}^{2}+x_{2}^{2}\right)^{3}} \ln \left(x_{1}^{2}+x_{2}^{2}\right)\right. \\
& \left.-4 x_{1} x_{2} \frac{x_{1}^{2}-x_{2}^{2}}{\left(x_{1}^{2}+x_{2}^{2}\right)^{3}} \arctan \left(\frac{x_{1}}{x_{2}}\right)\right] \\
& \frac{(1-(n-1) \bar{v}) \pi}{4 \mu} \chi_{1} \sigma_{22} \\
& =\frac{(1-(n-1) \bar{v})}{\mu} \chi_{1} p_{0} b \frac{x_{2}^{3}}{\left(x_{1}^{2}+x_{2}^{2}\right)^{2}} \\
& -\alpha \omega p_{0}^{2} \frac{b^{2}}{\pi}\left[\frac{11 x_{1}^{2}-5 x_{2}^{2}}{\left(x_{1}^{2}+x_{2}^{2}\right)^{3}}-\frac{3 x_{1}^{2}-x_{2}^{2}}{\left(x_{1}^{2}+x_{2}^{2}\right)^{3}} \ln \left(x_{1}^{2}+x_{2}^{2}\right)+8 \frac{x_{1} x_{2}}{\left(x_{1}^{2}+x_{2}^{2}\right)^{3}} \arctan \left(\frac{x_{1}}{x_{2}}\right)\right] x_{2}^{2} \\
& \frac{(1-(n-1) \bar{v}) \pi}{4 \mu} \chi_{1} \sigma_{12} \\
& =\frac{(1-(n-1) \bar{v})}{\mu} \chi_{1} p_{0} b \frac{x_{1} x_{2}^{2}}{\left(x_{1}^{2}+x_{2}^{2}\right)^{2}} \\
& -2 \alpha \omega p_{0}^{2} \frac{b^{2}}{\pi}\left[x_{1} \frac{3 x_{1}^{2}-5 x_{2}^{2}}{\left(x_{1}^{2}+x_{2}^{2}\right)^{3}}-x_{1} \frac{x_{1}^{2}-x_{2}^{2}}{\left(x_{1}^{2}+x_{2}^{2}\right)^{3}} \ln \left(x_{1}^{2}+x_{2}^{2}\right)+x_{2} \frac{x_{1}^{2}-x_{2}^{2}}{\left(x_{1}^{2}+x_{2}^{2}\right)^{3}} \arctan \left(\frac{x_{1}}{x_{2}}\right)\right] x_{2}
\end{aligned}
$$

が得られる.

\section{5. 数值計算例}

数値計算結果の一例を示す. ここでは, 計測温度 $\left(t / t_{0}\right)$, ならびに平面応力状態 $(n=2)$ における応力成分 $\left(\pi \sigma_{i j} / 4 \mu\right) の x_{2}=-h$ 面上での分布について調べた。 なお， 計測温度 ${ }^{(3)}$ とは,

$$
t=(1-\phi) t_{s}+\phi t_{g}
$$

で定義される多孔質体の局所的平均場に対する温度を意味する．ここで， $t_{g}$ は気体の温度であり，圧力解から $t_{g}=P / \rho R$ により得られる. 計算に用いた物性值を表 $1^{(3)}$ に示す. 本数值計算における境界条件は, 温度 $t_{0}=500 \mathrm{~K}$, 圧力 $p_{0}=4 \times 10^{5} \mathrm{~Pa}$ とし, 多孔質体の気孔率 $\phi=0.4$ で固定して透過係数を $\kappa / \varsigma=5 \times 10^{-10}, 3 \times 10^{-10}, 5 \times 10^{-11}$ と変化させた. また, $b=1[\mathrm{~m}]$ ならびに $h=1[\mathrm{~m}]$ とした.

Table 1 Physical parameters employed in this calculation ${ }^{(3)}$

\begin{tabular}{ccc}
\hline Nomenclature & Symbol & Assumed value \\
\hline Specific heat & $c_{p}[\mathrm{~J} / \mathrm{kg} \mathrm{K}]$ & 1000 \\
Gas density & $\rho\left[\mathrm{kg} / \mathrm{m}^{3}\right]$ & 1.3 \\
Gas constant & $R[\mathrm{~J} / \mathrm{kg} \mathrm{K}]$ & 287.03 \\
\hline Thermal conductivity of matrix & $\lambda_{s}[\mathrm{~W} / \mathrm{mK}]$ & 1.0 \\
\hline Elastic modulus & $E[\mathrm{GPa}]$ & 40.0 \\
\hline Poisson's ratio & $v$ & 0.3 \\
\hline Coefficient of thermal expansion & $\alpha[1 / \mathrm{K}]$ & $20 \times 10^{-6}$ \\
\hline
\end{tabular}


図 2 に得られた計算結果をまとめて示寸．図 2(a)は計測温度分布である.ここには，圧力解ならびに固体温度 解が偶関数であることを考慮して， $x_{1}>0, x_{2}=-h$ 領域の夕を示した. なお， $x_{1}<0, x_{2}=-h$ の領域における 計測温度は $x_{2}$ 軸に対称な分布となる. 図より, 計測温度は原点から離れるにつれて急速に低下していく.また, 透過係数に伴って計測温度は増加することがわかる．このような傾向が認められた理由として，多孔質体の透過 係数が高くなるにつれて表面から浸透した気体が多孔質体中を浸透しや寸くなり，このために透過係数に伴って 計測温度が高くなった。

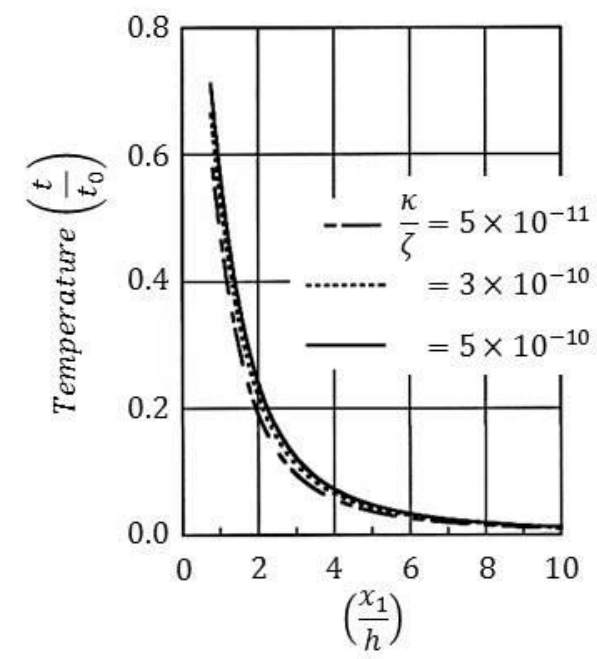

(a) Temperature distributions in a semi-infinite porous media

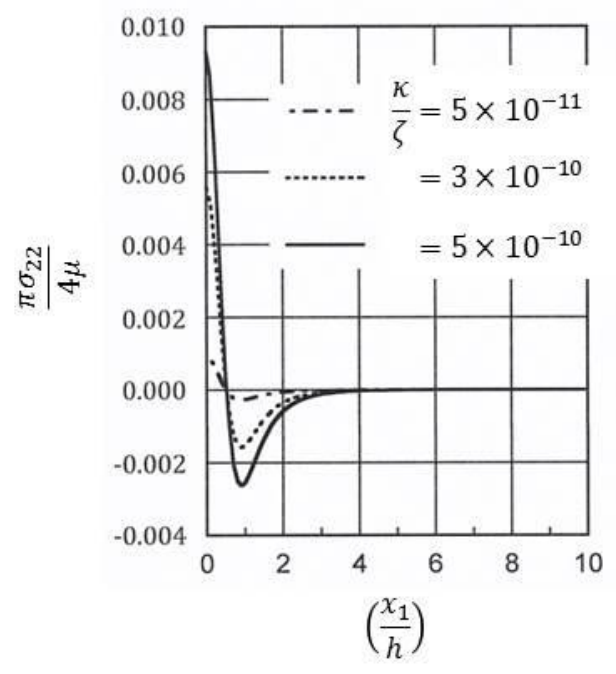

(b) Normal stress distributions

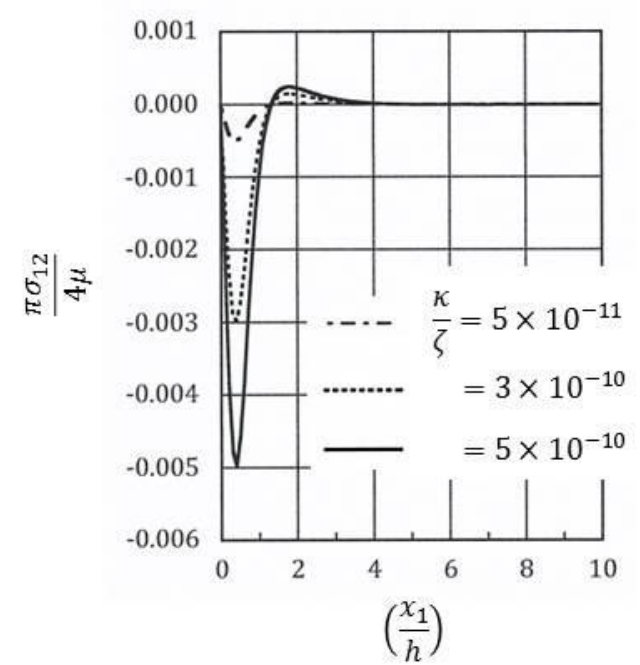

(c) Shear stress distributions

Fig.2 Numerical analysis results

図 2(b)，(c)は垂直応力 $\left(\pi \sigma_{22} / 4 \mu\right)$ ならびにせん断応力成分 $\left(\pi \sigma_{12} / 4 \mu\right)$ である. 垂直応力は $x_{2}$ 軸に対称な分布，せ 儿断応力は反対称な分布となる. 図において，先に示した計測温度分布と対応寸るようにしていずれの応力成分 においても透過係数に伴って応力值が増加する. $\left(x_{1} / h\right) \geq 1$ において, 垂直応力は表面から気体が圧入されるた め全体的に圧縮となる. せん断応力においても気体の圧入によって原点から $\left(x_{1} / h\right) \geq 1.7$ の領域において正方向 となる. これに対して $\left(x_{1} / h\right)<1$ の領域における垂直応力は, 圧縮応力から引張応力へと反転していく. 垂直応

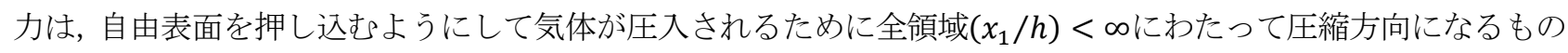
と考えられるが， $\left(x_{1} / h\right)<1$ 領域においてはこれと矛盾した結果になった. このような振る舞いは数学的に表 れた特異な現象と思われるが，今後の検討すべき課題と考えている，なお，紙面の都合上省略するが，垂直応力 
ならびにせん断応力分布はともに $x_{2}=-h$ 面が低下, 寸なわち表面から離れるにつれて面上の応力分布は減衰し ていく.

以上のことから，温度と圧力を集中して表面に受けることで多孔質半無限体に生じる熱応力は，気体の透過係 数 $(\kappa / \zeta)$ ならびに気体の膨張効果による影響を強く受けることがわかった.

\section{6. 結}

本論文では, 二次元多孔質半無限体の自由表面上に気体圧力, 温度を集中して受ける熱応力問題についてとり あげた. はじめに, 二次元問題のための気体圧力, 気体圧力と固体温度の連成方程式ならびに Navier の方程式を 導出した.つぎに Navierの方程式を変位ポテンシャル関数に関する非同次偏微分方程式に帰着させた. 解法には Fourier 変換法を用い, 本問題に対寸る気体圧力, 固体温度, 熱応力の厳密解を得た. 数值計算結果から, 多孔質 半無限体に生じる熱念力は透過係数に伴って増加することを示した.

\section{付 録 $\mathbf{A}$}

積分公式(5)

$$
\int_{-\infty}^{\infty} \frac{\ln \left|x_{1}\right|}{x_{1}} \exp \left(i \xi x_{1}\right) d x_{1}=-\pi i(\ln \xi+\gamma)
$$

を利用する．ここで， $\gamma$ はオイラーの定数

$$
\gamma=\lim _{n \rightarrow \infty}\left(1+\frac{1}{2}+\cdots+\frac{1}{n}-\ln (n)\right)
$$

である.これをそで積分して，

$$
\int_{-\infty}^{\infty} \frac{\ln \left|x_{1}\right|}{x_{1}^{2}} \exp \left(i \xi x_{1}\right) d x_{1}=\pi \xi(\ln \xi-1+\gamma)
$$

を得る.この積分は, 積分核の性質を考慮すれば

$$
\int_{0}^{\infty} \frac{\ln \left|x_{1}\right|}{x_{1}^{2}} \cos \left(\xi x_{1}\right) d x_{1}=\frac{\pi}{2} \xi(\ln \xi-1+\gamma)
$$

のように変形できる.

\section{付 録 B}

$$
\int_{0}^{\infty} \exp \left(\xi x_{2}\right) \cos \left(\xi x_{1}\right) d \xi=-\frac{x_{2}}{x_{1}^{2}+x_{2}^{2}}
$$

を $x_{2}$ で微分して, 


$$
\int_{0}^{\infty} \xi \exp \left(\xi x_{2}\right) \cos \left(\xi x_{1}\right) d \xi=-\frac{\left(x_{1}^{2}-x_{2}^{2}\right)}{\left(x_{1}^{2}+x_{2}^{2}\right)^{2}}
$$

を得る。また，

$$
\int_{0}^{\infty} \exp \left(\xi x_{2}\right) \sin \left(\xi x_{1}\right) d \xi=\frac{x_{1}}{x_{1}^{2}+x_{2}^{2}}
$$

を $x_{2}$ で微分することで,

$$
\int_{0}^{\infty} \xi \exp \left(\xi x_{2}\right) \sin \left(\xi x_{1}\right) d \xi=-\frac{2 x_{1} x_{2}}{\left(x_{1}^{2}+x_{2}^{2}\right)^{2}}
$$

\section{を得る。}

積分公式(6)

$$
\int_{0}^{\infty} \exp (-q x) \cos (p x) \ln x d x=\frac{-1}{p^{2}+q^{2}}\left[\frac{1}{2} q \ln \left(p^{2}+q^{2}\right)+\operatorname{parctan}\left(\frac{p}{q}\right)+q \gamma\right]
$$

に対して $, x \rightarrow \xi, p \rightarrow x_{1}, q \rightarrow-x_{2}$ と置き換えると，

$$
\int_{0}^{\infty} \exp \left(\xi x_{2}\right) \cos \left(\xi x_{1}\right) \ln \xi d \xi=\frac{1}{x_{1}^{2}+x_{2}^{2}}\left[\frac{1}{2} x_{2} \ln \left(x_{1}^{2}+x_{2}^{2}\right)+x_{1} \arctan \left(\frac{x_{1}}{x_{2}}\right)+x_{2} \gamma\right]
$$

を得る。

一方，式(B-1)より，

$$
\int_{0}^{\infty} \gamma \exp \left(\xi x_{2}\right) \cos \left(\xi x_{1}\right) d \xi=-\frac{\gamma x_{2}}{x_{1}^{2}+x_{2}^{2}}
$$

このふたつの積分公式を組み合わせることで，つぎの積分公式

$$
\int_{0}^{\infty}(\ln \xi+\gamma) \exp \left(\xi x_{2}\right) \cos \left(\xi x_{1}\right) d \xi=\frac{x_{2} \ln \left(x_{1}^{2}+x_{2}^{2}\right)}{2\left(x_{1}^{2}+x_{2}^{2}\right)}+\frac{x_{1}}{x_{1}^{2}+x_{2}^{2}} \arctan \left(\frac{x_{1}}{x_{2}}\right)
$$

\section{を得る.}

式(B-7)を $x_{2}$ で微分すると，

$$
\int_{0}^{\infty} \xi(\ln \xi+\gamma) \exp \left(\xi x_{2}\right) \cos \left(\xi x_{1}\right) d \xi=\frac{\left(x_{1}^{2}-x_{2}^{2}\right)}{2\left(x_{1}^{2}+x_{2}^{2}\right)^{2}}\left\{\ln \left(x_{1}^{2}+x_{2}^{2}\right)-2\right\}-2 \frac{x_{1} x_{2}}{\left(x_{1}^{2}+x_{2}^{2}\right)^{2}} \arctan \left(\frac{x_{1}}{x_{2}}\right)
$$

また式(B-7)を $x_{1}$ で微分することで，

$$
\int_{0}^{\infty} \xi(\ln \xi+\gamma) \exp \left(\xi x_{2}\right) \sin \left(\xi x_{1}\right) d \xi=\frac{x_{1} x_{2}}{\left(x_{1}^{2}+x_{2}^{2}\right)^{2}}\left\{\ln \left(x_{1}^{2}+x_{2}^{2}\right)-2\right\}+\frac{\left(x_{1}^{2}-x_{2}^{2}\right)}{\left(x_{1}^{2}+x_{2}^{2}\right)^{2}} \arctan \left(\frac{x_{1}}{x_{2}}\right)
$$


を得る。

さらに式(B-8)を $x_{2}$ で微分すると，

$\int_{0}^{\infty} \xi^{2}(\ln \xi+\gamma) \exp \left(\xi x_{2}\right) \cos \left(\xi x_{1}\right) d \xi$

$$
=x_{2} \frac{\left(-3 x_{1}^{2}+x_{2}^{2}\right)}{\left(x_{1}^{2}+x_{2}^{2}\right)^{3}}\left\{\ln \left(x_{1}^{2}+x_{2}^{2}\right)-3\right\}-2 x_{1} \frac{\left(x_{1}^{2}-3 x_{2}^{2}\right)}{\left(x_{1}^{2}+x_{2}^{2}\right)^{3}} \arctan \left(\frac{x_{1}}{x_{2}}\right)(B-10)
$$

あるいは $x_{1}$ で微分して,

$\int_{0}^{\infty} \xi^{2}(\ln \xi+\gamma) \exp \left(\xi x_{2}\right) \sin \left(\xi x_{1}\right) d \xi$

$$
=x_{1} \frac{\left(x_{1}^{2}-3 x_{2}^{2}\right)}{\left(x_{1}^{2}+x_{2}^{2}\right)^{3}}\left\{\ln \left(x_{1}^{2}+x_{2}^{2}\right)-3\right\}-2 x_{2} \frac{\left(x_{1}^{2}-x_{2}^{2}\right)}{\left(x_{1}^{2}+x_{2}^{2}\right)^{3}} \arctan \left(\frac{x_{1}}{x_{2}}\right) \quad(B-11)
$$

を得る.

\section{文献}

(1) 竹内洋一郎, 熱応力 (1989), 日新出版, pp. 57-61.

(2) 山田勝稔, 大石篤哉, “表面が局部加熱される接合膜をもつ半無限体の熱応力とその消失条件”, 日本機械学会論文 集 A 編，Vol.60, No.577 (1994), pp.1979-1984.

(3) 荒井正行, “気体浸透と熱伝導を受ける多孔質体の熱応力について”, 日本機械学会論文集 A 編, Vol.78, No.787 (2011), p.336-348.

(4) Sneddon, I. N., Fourier Transforms (1995), Dover Publications, Inc., pp.7-29.

(5) 森口繁一, 宇田川金圭久, 一松信, 岩波 数学公式 (II) 級数・フーリエ解析 (1992), 岩波書店, p.278.

(6) Gradshteyn, I. S., Ryzbik, I. M., Table of Integrals, Series and Products, (2000), Academic Press, p.595. 